\title{
Re-sleeve Gastrectomy for Failure of Weight Loss After Primary Sleeve Gastrectomy; 3 Cases
}

\author{
Ji-Sun Hong and Sang-Moon Han* \\ Department of Surgery, Gangnam CHA Medical Center, School of Medicine, CHA University, Seoul, Korea
}

\begin{abstract}
Laparoscopic sleeve gastrectomy (LSG) is the leading weight loss procedure for treatment of morbid obesity. However, as with all other bariatric procedures, failure of weight loss was observed. We report here 3 cases of resleeve gastrectomy (RSG) for failure of weight loss after primary sleeve gastrectomy (PSG). The first patient, with a body mass index (BMI) of $32.9 \mathrm{~kg} / \mathrm{m}^{2}$, underwent PSG in August 2003. She showed an initial drop in BMI to 22.4 $\mathrm{kg} / \mathrm{m}^{2}$ in 2007 and regained weight to BMI of $33.1 \mathrm{~kg} / \mathrm{m}^{2}$ in 2013, but, after the RSG, her BMI was $21.9 \mathrm{~kg} / \mathrm{m}^{2}$ at 12 months. The second patient, with a BMI of $32.6 \mathrm{~kg} / \mathrm{m}^{2}$, underwent PSG in May 2004. She showed a drop in BMI of $27.4 \mathrm{~kg} / \mathrm{m}^{2}$ in 2005 and regained weight to BMl of $31.4 \mathrm{~kg} / \mathrm{m}^{2}$ in 2011 , but, after the RSG, her BMI was $24.4 \mathrm{~kg} / \mathrm{m}^{2}$ at 24 months. The third patient, with a BMI of $34.0 \mathrm{~kg} / \mathrm{m}^{2}$, underwent PSG in July 2013 . She had a drop in BMI of $28.0 \mathrm{~kg} / \mathrm{m}^{2}$ in January 2014, but her weight did not change until July 2014. Her BMI had dropped to 21.2 at 6 month postoperatively after RSG. Therefore, RSG may be considered as a revision surgery for failure of weight loss after PSG.
\end{abstract}

Keywords: Primary sleeve gastrectomy; Failure of weight loss; Fundus dilatation; Re-sleeve gastrectomy

\section{Introduction}

The advantages of laparoscopic sleeve gastrectomy (LSG) include excellent weight loss, resolution of co-morbidities, relatively simple technique, avoidance of foreign body, relatively short operation time, immediate restriction of caloric intake and low incidence of complications $[1,2]$. Over the years, many bariatric surgeons have regarded it as a standard bariatric operation. Despite many advantages following LSG, as with all other bariatric procedures, failure of weight loss was observed [3-6]. There is no consensus regarding conversion procedures for additional weight loss after primary sleeve gastrectomy (PSG). Therefore, many other procedures were performed worldwide [7]. In this case study, we report on three patients who underwent resleeve gastrectomy (RSG) as a revision procedure for failure of weight loss after PSG.

\section{Case Report}

\section{Patient 1}

A 32-year-old female with a body mass index (BMI) of $32.9 \mathrm{~kg} /$ $\mathrm{m}^{2}$ underwent PSG in August 2003. Her lowest BMI was $22.4 \mathrm{~kg} / \mathrm{m}^{2}$ at 42 months post-PSG, and then she regained weight to BMI of $33.1 \mathrm{~kg} /$ $\mathrm{m}^{2}$ in 2013. Upon review of the upper gastrointestinal series (UGIS), upper pouch and antral dilatation were detected (Figures 1 and 2). She underwent RSG using a 36F bougie in December 2013, with resection of the dilated pouch and antrum. A point on the greater curvature $3 \mathrm{~cm}$ proximal to the pylorus was identified as the distal extent of the resection. After RSG, her BMI was $21.9 \mathrm{~kg} / \mathrm{m}^{2}$ at 12 months, with excess BMI loss (\%EBL) of $111.1 \%$.

\section{Patient 2}

A 51-year-old female with a BMI of $32.6 \mathrm{~kg} / \mathrm{m}^{2}$ underwent PSG in May 2004. Her lowest BMI was $27.4 \mathrm{~kg} / \mathrm{m}^{2}$ at 9 months post-PSG, and then she regained weight to BMI of $31.4 \mathrm{~kg} / \mathrm{m}^{2}$ with hypertension and hyperlipidemia in 2011. Diffuse dilatation of the stomach was detected on UGIS (Figures 3 and 4). RSG was performed in December 2011. After RSG, gastric stricture was observed, but no additional procedure was performed. Her BMI was $24.4 \mathrm{~kg} / \mathrm{m}^{2}$ at 24 months, with $\% \mathrm{EBL}$ of $83.3 \%$.

\section{Patient 3}

A 33-year-old female with a BMI of $34.0 \mathrm{~kg} / \mathrm{m}^{2}$ underwent PSG in July 2013. Her lowest BMI was $28.0 \mathrm{~kg} / \mathrm{m}^{2}$ at 6 months post-PSG with $\% \mathrm{EBL}$ of $54.4 \%$, and her weight did not change until after 12 months postoperatively. Remnant fundus dilatation of the stomach was detected on UGIS (Figure 5). RSG was performed in July 2014. After RSG, her BMI was $21.2 \mathrm{~kg} / \mathrm{m}^{2}$ at 6 month, with $\% \mathrm{EBL}$ of $116.0 \%$.

\section{Discussion}

LSG has been most commonly performed in Asia due to minimized

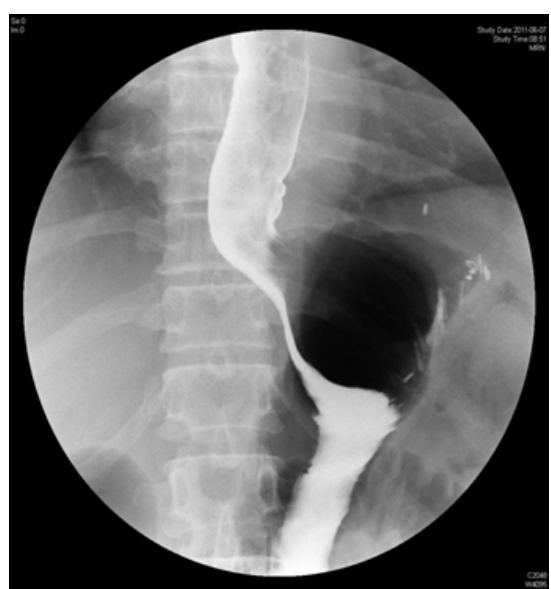

Figure 1: The upper gastrointestinal series showing dilatation of fundus.

*Corresponding author: Sang-Moon Han, Department of Surgery, Gangnam CHA Medical Center, School of Medicine, CHA University, Seoul, Korea, 135-913, Tel: 02-3468-3369; Fax: 02-34683507; E-mail: surgeryhan@gmail.com

Received July 29, 2015; Accepted August 20, 2015; Published August 25, 2015

Citation: Hong JS, Han SM (2015) Re-sleeve Gastrectomy for Failure of Weight Loss After Primary Sleeve Gastrectomy; 3 Cases. J Metabolic Synd 4: 182 doi:10.4172/2167-0943.1000182

Copyright: $\odot 2015$ Hong JS, et al. This is an open-access article distributed under the terms of the Creative Commons Attribution License, which permits unrestricted use, distribution, and reproduction in any medium, provided the original author and source are credited. 


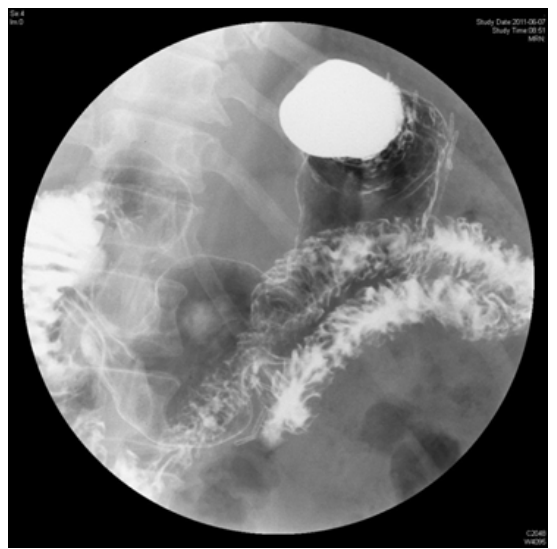

Figure 2: The upper gastrointestinal series showing diffuse antral dilatation.

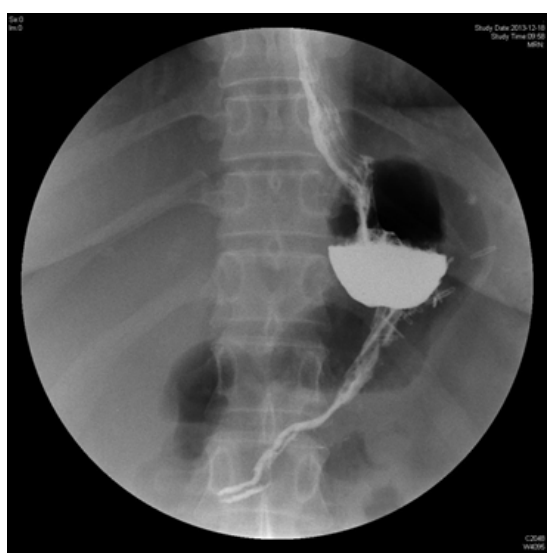

Figure 3: Remnant fundus dilatation.

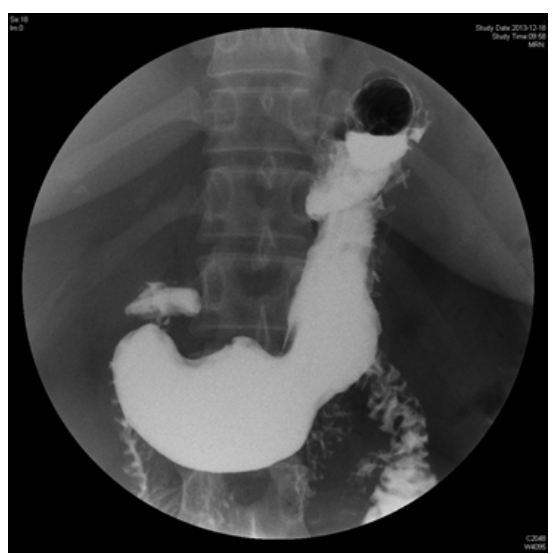

Figure 4: Diffuse antral dilatation on upper gastrointestinal series.

risk of undetected gastric cancer, incredible short and mid-term weight loss, and low post-operative complications [8]. Despite many advantages following LSG, failure of weight loss was observed, and a revision procedure had to be considered for achievement of additional weight loss.

Two patients started to regain weight after 3 to 5 years postPSG. One patient did not experience weight loss after 6 months. The
UGIS showed dilated antrum and/or gastric fundus in all 3 patients. Although the causes of remnant gastric dilatation are unclear, it might be related to a technical problem or to a natural process of stomach tissue dilatation. The main technical cause for dilated antrum might be a dissection that started farther than $6 \mathrm{~cm}$ from the pylorus. In 2003 and 2004, at the time of its introduction, PSG was performed far from $6 \mathrm{~cm}$ pylorus. Therefore, this is one cause of weight regain after a few years. The $4^{\text {th }}$ International Consensus Summit on Sleeve Gastrectomy (ICSSG) recently reported [7] that the resection distance from the pylorus was not above $4 \mathrm{~cm}$. In addition, in prospective randomized study, Abdallah et al. [9] reported that $2 \mathrm{~cm}$ resection distance from the pylorus is associated with better weight loss without increasing the rate of complications. In particular, the lower weight regain rate (1.9\%) at 2 $\mathrm{cm}$ compared with $6 \mathrm{~cm}(9.4 \%)$ distance from the pylorus was reported after 2 years. For this reason, the stomach should be resected less than $4 \mathrm{~cm}$ distance from the pylorus during PSG.

Another cause of weight regain after PSG might be a dilatation of the remnant stomach. Many efforts and standardization of PSG to reduce weight loss failure were reported. The $4^{\text {th }}$ ICSSG [7] reported that of the 130 surgeons, $40(32 \%)$ use a $36 \mathrm{~F}$ bougie, which was the most common size selected within a wide range of 32-50F. In addition, the International Sleeve Gastrectomy Expert Panel Consensus Statement for best practice guidelines [2] concluded that a bougie not wider than $32-36 \mathrm{~F}$ should be used in the LSG procedure. Other causes of stomach tissue dilatation after PSG, besides technical problems, could be related to psychological problems of the patient or negligence in following the post-surgical dietary recommendations. We believe that these factors, technical and not, are often both involved in the process of weight regain after PSG.

There is no consensus regarding conversion procedures for additional weight loss after PSG, and there are few surgical options. LSG can be converted to gastric bypass or duodenal switch [10-12], or a RSG can be performed $[13,14]$. In our study, we wanted to maintain the advantages of LSG in terms of avoiding malabsorption or gastrointestinal anastomosis in order to easily explore the gastro-intestinal tract in the necessity of diagnostic endoscopy; therefore no patients underwent gastric bypass or duodenal switch. In particular, 3 patients had lower BMI $\left(<35 \mathrm{~kg} / \mathrm{m}^{2}\right)$ at the previous PSG and at the time of RSG. Three patients underwent RSG using a $36 \mathrm{~F}$ bougie and an over sewing suture of the stapled line was performed. In our previous study [15] in patients with lower BMI, PSG was a very effective and safe procedure in the long-term period. In particular, patients using a $36 \mathrm{~F}$ bougie had higher $\% \mathrm{EBL}(110 \%)$ than patients using a $48 \mathrm{~F}$ bougie

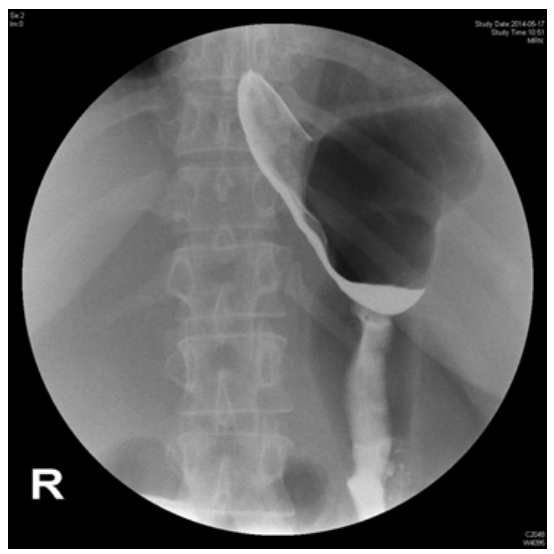

Figure 5: Persistence of the gastric fundus on upper gastrointestinal series. 
Citation: Hong JS, Han SM (2015) Re-sleeve Gastrectomy for Failure of Weight Loss After Primary Sleeve Gastrectomy; 3 Cases. J Metabolic Synd 4: 182. doi:10.4172/2167-0943.1000182

(81\%) at 1 year postoperatively. For this reason, we do not recommend gastric bypass or duodenal switch in these patients. However, in case of BMI more than $40 \mathrm{~kg} / \mathrm{m}^{2}$, no resolution of diabetes, or severe GERD, we could recommend another procedure including gastric bypass or duodenal switch.

RSG was feasible in our series. However, we experienced one stricture of the remnant stomach. The further procedure was not required for the treatment of this complication. However, this patient had recurrent epigastric discomfort and vomiting when eating food for 1 month after RSG.

Although the \% EBL of 3 patients after RSG was excellent, a longer follow-up period is needed in order to determine whether RSG is really effective. These data are encouraging in not substituting LSG with a malabsorbitive intervention. If weight regain occurs after a longer follow-up post-RSG, we will check UGIS. If UGIS shows a dilatation of the stomach, another RSG will be performed. If patients regain weight without dilatation of the remnant stomach, malabsorbitive intervention will be recommended.

In conclusion, PSG can result in weight regain. In pouch dilatation of patients who regained weight after PSG, RSG was performed and was effective in the short-term period. RSG appears to be a valid correction for weight regain after PSG. However, we believe that these data could be a promising start for further studies, which are needed to confirm the initial results.

\section{Conflicts of Interest}

No potential conflict of interest relevant to this article was reported.

\section{References}

1. Brethauer SA, Hammel JP, Schauer PR (2009) Systemic review of sleeve gastrectomy as staging and primary bariatric procedure. Surg Obes Relat Dis 5: 469-75.

2. Rosenthal RJ (2012) International sleeve gastrectomy expert panel consensus statement best practice guidelines based on experience of $>12000$ cases. Surg Obes Relat Dis 8: 8-19.

3. Nguyen NQ, Game P, Bessell J, Debreceni TL, Neo M, et al. (2013) Outcomes of Roux-en-Y gastric bypass and laparoscopic adjustable gastric banding World J Gastroenterol 19: 6035-6043.

4. Langer FB, Bohdjalian A, Shakeri-Manesch S, Felberbauer FX, Ludvik B et al. (2008) Inadequate weight loss vs secondary weight regain: laparoscopic conversion from gastric banding to Roux-en-Y gastric bypass. Obes Surg18: $1381-1386$.

5. Magro DO, Geloneze B, Delfini R, Pareja BC, Callejas F, et al. (2008) Longterm weight regain after gastric bypass: a 5 -year prospective study. Obes Surg18: 648-651.

6. Christou NV, Look D, Maclean LD (2006) Weight gain after short- and longlimb gastric bypass in patients followed for longer than 10 years. Ann Surg 244: 734-740

7. Gagner M, Deitel M, Erickson AL, Crosby RD (2013) Survey on laparoscopic sleeve gastrectomy (LSG) at the fourth international consensus summit on sleeve gastrectomy. Obes Surg 23: 2013-2017.

8. Lomanto D, Lee WJ, Goel R, Lee JJ, Shabbir A, et al. (2012) Bariatric surgery in Asia in the last 5 years (2005-2009). Obes Surg 22: 502-506.

9. Abdallah E, El Nakeeb A, Yousef T, Abdallah H, Ellatif MA, et al. (2014) Impact of extent of antral resection on surgical outcomes of sleeve gastrectomy for morbid obesity (a prospective randomized study). Obes Surg 24: 1587-1594.

10. Bohdjalian A, Langer FB, Shakeri-Leidenmuhler S, Gfrerer L, Ludvik B, et al. (2010) Sleeve gastrectomy as sole and definitive bariatric procedure: 5-year results for weight loss and ghrelin. Obes Surg 20: 535-540.

11. Sarela AI, Dexter SP, O'Kane M, Menon A, McMahon MJ (2012) Long-term follow-up after laparoscopic sleeve gastrectomy: 8-9-year results. Surg Obes Relat Dis 8: 679-84.

12. Dapri G, Cadière GB, Himpens J (2011) Laparoscopic repeat sleeve gastrectomy versus duodenal switch after isolated sleeve gastrectomy for obesity. Surg Obes Relat Dis 7: 38-43.

13. Iannelli A, Schneck AS, Noel P, Ben Amor I, Krawczykowski D, et al. (2011) Re-sleeve gastrectomy for failed laparoscopic sleeve gastrectomy: a feasibility study. Obes Surg 21: 832-835.

14. Noel P, Nedelcu M, Nocca D, Schneck AS, Gugenheim J, et al. (2014) Revised sleeve gastrectomy: another option for weight loss failure after sleeve gastrectomy. Surg Endosc 28: 1096-1102.

15. Hong JS, Kim WW, Han SM (2015) Five-year results of laparoscopic sleeve gastrectomy in Korean patients with lower body mass index $\left(30-35 \mathrm{~kg} / \mathrm{m}^{2}\right)$ Obes Surg 25: 824-829. 